\title{
Archaeological Significances of the Potmaking Tradition of the Oinamee in Manipur (India)
}

\author{
Khangembam Vidyani ${ }^{1}$ and Mayanglambam ManiBabu ${ }^{2}$ \\ ${ }^{I}$ Research Scholar, ${ }^{2}$ Professor, \\ Department of Anthropology, Manipur University, Canchipur, Imphal-795 003, India
}

\begin{abstract}
The present paper tries to gives an account of the manufacturing process of pottery by the people of Oinam, who inhabit the same named village in the Senapati District, Manipur (India), among whom the art of potmaking is still a continuing craft since early days the significance of Oinam ceramic technology lies with the fact that this female-oriented craft is excelled with the naked hand by using molding and paddle-beater technique duly decorated with cord-marked impression at the body part of the vessels. Both these ceramic attributes bear archaeological significances in terms of their probable spatial distribution and continuity throughout Southeast Asia and beyond since Neolithic times or earlier.
\end{abstract}

Keywords: Handmade pottery, cord-marking, Oinam, Poumai tribe, Naga, Manipur (India)

\section{Introduction}

The contemporary societies are quite different from their past predecessors and there exists very little one-to-one relationship between the present and past societies. However, ethnographic studies try to bridge this gap by identifying the analogical characters as well as cultural changes which may have taken place, thereby leading to a better understanding of the archaeological record ${ }^{[1]}$. This area of study is the subject matter of ethnoarchaeology - the use of ethnography by archaeologists in interpreting the past material traces. Ethnoarchaeological studies have become an important means for understanding the complex relationships between material culture and human behaviour ${ }^{[2] ~[3] ~[4] . ~ H e r e, ~ a n a l o g i c a l ~ i n f e r e n c e s ~ a n d ~ t h e ~ p r i n c i p l e s ~ o f ~}$ uniformitarianism lie at the basis of such studies. Ethnoarchaeology is a way to animate the "static" remnants of the past, and the study of it can be done either "by collecting ethnographic data from communities living near the archaeological sites under investigation or from societies that, owing to their perceived "premodern" way of life, were deemed appropriate to be compared with archaeological contexts ${ }^{[5]}$. The frame of the present paper is on the later pursuit of ethnoarchaeology and particularly on ceramics. Ceramics as an important material remains are abundantly found in many of the archaeological sites. These are formed with clay and tempering material and made durable by firing. Understanding of the relationship between patterned behaviour and elements of material culture that may be preserved in the archaeological record is one of the objectives of ethnoarchaeology.

The present paper deals with the pottery making tradition of the Poumai tribe of Manipur (India), which is one of the main constituent groups of the Naga community who inhabit the Oinam village. The village is located at an altitude of about 5500 feet above msl lies at a distance of about $40 \mathrm{~km}$ away from Senapati District headquarter and about $16 \mathrm{~km}$ away from Maram Town along the National Highway No. 2 in the Senapati District, Manipur (India). Here, archaeological significance of the potmaking tradition of the Poumais is briefly discussed. The craft of making pot (locally known as pouli) is one of the unique characters of the people since the art is not known to other Naga people in the District. And the legacy of pottery making is interwoven with the history of origin of the village. The story of migration of the tribe runs with a legend that the ancestors of the Oinam village migrated from Makhel area (a place located to the northern side of the village). Before leaving Makhel, the ancestors of the Oiname (the people of Oinam) got a divinely directive with a packet of meal through their ancestral mother. The ancestral mother also advised them to settle to an area where rooster did crow. Accordingly both ancestor and ancestress of the Oiname along with some other people preceded their exodus down towards Barak valley in the west. They then proceeded upwards to the south through a place called Nghaphouzherange. When they reached Koide village they open a packet of the meal which their ancestral mother gave to them, and they found a cat's head inside. They could then remember the word of the ancestral mother which says 'the man in whose meal pack contained cat's head is the eldest in the family'. They were happy. However as they did not have any divinely signal to settle down there, they started moving towards the area in and around the present Oinam village for searching a suitable place to settle. As they reached Oinam, they heard crowing by a rooster. Then the ancestress dug up the earth with her walking stick and smelt the soil. She felt the smelling quite similar with the soil availed at Makhel. They choose the area and since then they settled down at the present Oinam village as their permanent habitation. 
The patri-oriented agrarian Poumais obtain their subsistence primarily through wet terrace cultivation. In the household, men and women are involved in different activities to ensure the availability of goods and services for family consumption and well-being. According to their gender-based division of labor - females, besides engaging in tilling the terrace fields along with their males, have primary responsibility for householdrelated activities. They engaged themselves in spinning and weaving on their loom to provide clothing to the whole family members besides making earthen pots which are done on part-time basis in the dry seasons when they are free from the agricultural works. The womenfolk get absorbed in the craft of potmaking after the rainy season, starting in the month of November and continue till June. Manufacturing of earthen pot is a virtual monopoly of the Poumais of the Oinam village from time immemorial, and their counterparts of other neighbouring village are not allowed to do so. Further, pottery making is also an exclusive domain of womenfolk; it is a taboo for menfolk to excel the craft. Both married and unmarried women can engage themselves in this craft. Females whose origins are not from Oinam cannot posit in the craft. It is also believed that if women of Oinam village make pots outside the village boundary, pot would crack during its firing. However, a woman of Oinam who returns and resettles in her natal village owing to divorce or otherwise can continue making pots.

\section{Oinam System Of Pottery Making}

A wide range of earthen vessels are made and used by the people in their daily chores, and some of these are the indispensable items in the religious affairs. They classify their pottery on the basis of the design of the pots which reflects the morphological projection of their usage. This functional-based classificatory system focuses on different parameters of the vessel, such as, size, shape, presence or absence of decoration and other factors. On the basis of the function, the Oinam pots may be classified into utilitarian and non-utilitarian group. Manufacturing the earthen vessel is a long process right from ceramic resource procurement to firing through the stages of processing of resources (clay and tempering material), mixing and pounding the resources, giving different shapes and sizes, decoration, etc. Clay and temper being the primary ceramic resources, form the important items responsible for the development of the craft of pottery making among the population.

Three kinds of potting raw material are known to the craftsperson - such as, Dongae (black in colour), Ngasou (Brown in colour) and Ngahei (red in colour). Dongae and Ngasou form the primary tempering material. The potters collect the ceramic resources from different sites of the village. Dongae (black clay) is collected from a site called Kure/Voh which is located at a geodesic distance of about two and half $\mathrm{km}$, and pheric distance is of about an hour and forty five minutes from the village (ManiBabu, 2006b). Ngasou (brown clay) is collected from the site called Thai/Phai/Ture Taro. The geodesic and pheric distances to this location from the village are of about two $\mathrm{km}$ and are sixty minutes (ibid). Respectively the red clay (ngahei) is collected from the site called Runo, having its geodesic and pheric distance of about one $\mathrm{km}$ and thirty minutes (ibid). Collection of these resources are done by the potters in groups and before digging the site they pray the custodial deity of the site to protect them from any harmful acts during potmaking. After that they start digging horizontally with the help of a hoe. These clays are found from a depth of about one to two feet or more below the ground surface. (Fig. 1)
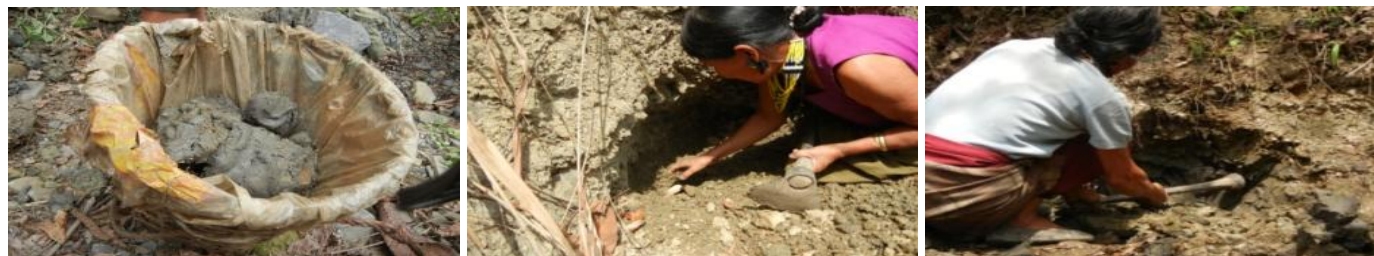

Fig: 1- Collecting clay and tempering material from the respective resource sites by the Oinam Poumai craftsperson

Table 1: Characteristic features of the three types of Oinam potting clay (Source: Imoba et.al. 1999:32)

\begin{tabular}{|l|l|l|l|l|}
\hline \multirow{2}{*}{ Type } & \multicolumn{2}{|l|}{ Consistency percent } & \multirow{2}{*}{ Plasticity index } \\
\cline { 2 - 4 } & Clay & Sand & Silt & \\
\hline Black Clay & 56.2 & 23.1 & 20.7 & 12.9 \\
Brown Clay & 60.3 & 20.4 & 19.3 & 14.1 \\
Red Clay & 61.7 & 19.8 & 18.5 & 14.6 \\
\hline
\end{tabular}

The other equally important secondary ceramic resources like fuel, husk/chaff, colouring material and water are readily available nearby the potters' house in their surroundings. They used straw, dry shrub and small woods (called mothing) as fuel. Since Oinam people practice agriculture, straw is available in abundance; they stored the straw after harvesting the fields. The colouring material made from the bark of a tree called 'paothing' 
is collected from the nearby forest area and also available near potters' house. Important items and appliances used by the craftsperson in making earthen vessels are as follows:

Mi/Mee (wooden pestle): It is a cylindrical wooden pestle (which is of about $80 \mathrm{~cm}$ in length, $40 \mathrm{~cm}$ in breadth and $5 \mathrm{~cm}$ in thickness) used for pounding the primary ceramic resources by placing in a mortar (Fig -2a).

Ngaeabung/Ngakung (mortar): It is a dug-out rectangular wooden mortar used for pounding clay and tempering material together with the help of the pestle. It generally measures about 100 x 30 x13 cms. (Fig-2b).

Pheng (platform): It is used as a seat by the potter while making pot (Fig -3).

Ngeajande/De (sieve): It is made of split bamboo or cane in order to sieve the pounded earthy materials. Coarse granules that do not pass through the sieve are again pounded and shifted. It usually measures $30 \mathrm{~cm}$. in length, $28 \mathrm{~cm}$ in breadth with a depth of about $5 \mathrm{~cm}(\mathrm{Fig}-4 \mathrm{a})$.

$\mathrm{Wu} / \mathrm{Vu}$ (roller):-It is a solid cylindrical wooden rod used as a mould for wrapping the paste. It generally measures about $44.5 \mathrm{~cm}$ in length and $4 \mathrm{~cm}$ in circumference. (Fig- $4 \mathrm{~b}$ )

Titu (beater):-It is used to pat the outer surface to achieve required shape and thickness of the pot. It usually measures around 27 to $30 \mathrm{~cm}$. in length. (Fig -5a)

Khouthing (heavy beater):- A wooden plain beater which is used in shaping the pot by dapping the outer surface with 'khouthing'. It is a very important tool during a stage of pot making where shape of the pot is to achieve. It usually measures $33 \mathrm{~cm}$. in length, $2.0 \mathrm{~cm}$. in breadth and $1.0 \mathrm{~cm}$. in thickness. (Fig-5b)

Zha (smoother):- It is a thin bamboo split used to scrap the unwanted clay from the body of the pot so as to obtain an even surface or to make smooth of certain types of earthenware. (Fig-6a)

Tuta (protector):-It is a stone pebble, oval in shape used as an anvil. It is inserted through the mouth and used to prop the inner wall. It generally measures a maximum length of $10 \mathrm{~cm}$, breadth of $6 \mathrm{~cm}$ and thickness of $4.6 \mathrm{~cm}$. (Fig -6b)

Piisu (wooden protector):- A wooden protector is used as a support during making a pot. It usually measures 18 $\mathrm{cm}$ in length and $6.4 \mathrm{~cm}$. in diameter. (Fig 7a)

Khya/Khea (Designer); - A net-wrapped wooden paddle. One end of it is wrapped with a piece of bamboo-plaited net made out of strips of bamboo (of 'poh' species). This appliance is mainly used for decorating the outer walls of the green pots. The maximum length measured is about $24.9 \mathrm{~cm}, 4.0 \mathrm{~cm}$ in breadth and $3.0 \mathrm{~cm}$ in thickness. (Fig-7b)

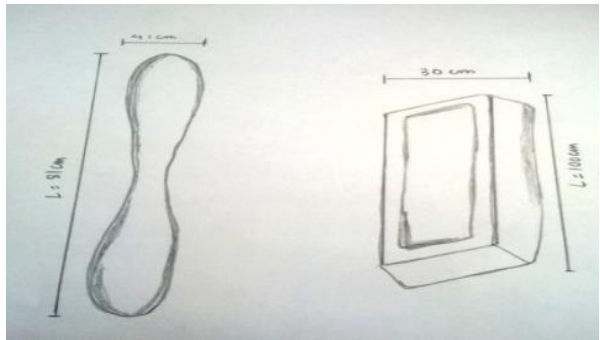

Fig2. (a) Pestle (Mee), (b) Mortar (Ngaeabung)

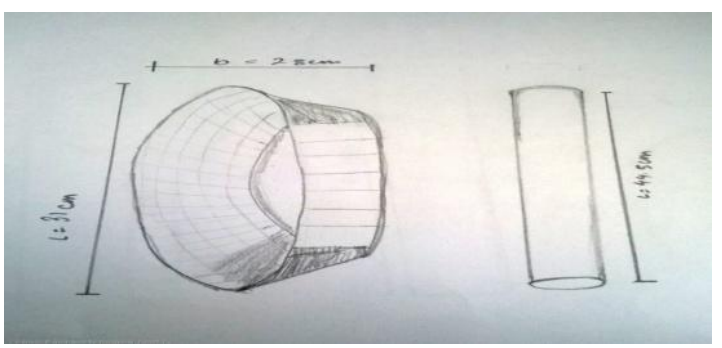

Fig 4. (a) Sieve (De), (b) Roller (Vu)

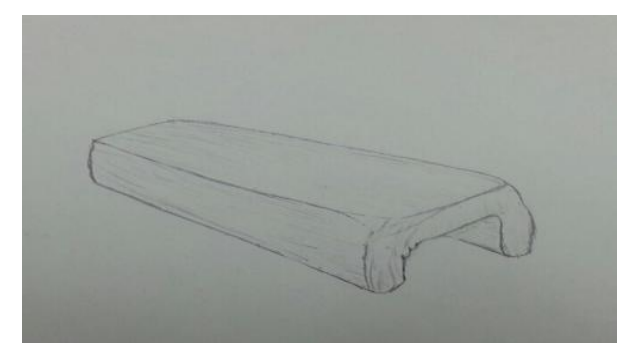

Fig 3. Seat of the potter (Pheng)

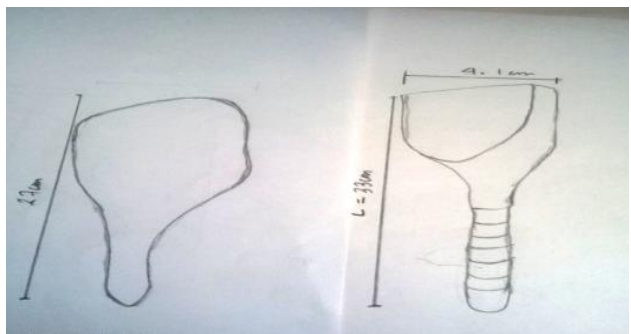

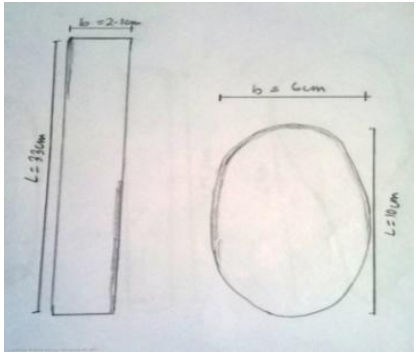

Fig:6. (a) Smoother (Zha), (b) Protector (Tuta)
Fig 5. (a) Beater (Titu), (b) Heavy beater (Khouthing)

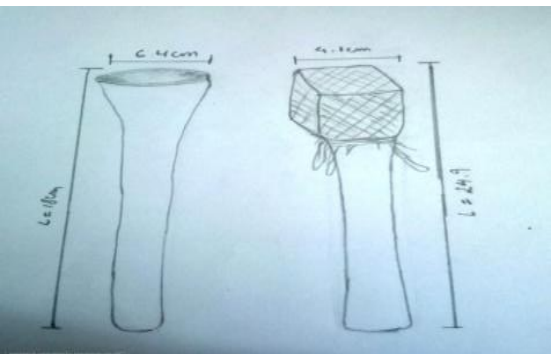

Fig:-7. (a)Wooden protector,(b)Cord-marked paddle (Khya) 


\subsection{Primary Ceramic Resources}

The three kinds of earthen materials, used in making pots, after their exploitation from respective resource sites, are first exposed to sunlight to dry ranging from about four to five days or even longer depending on the weather condition. After getting dried, these are mixed together in a ratio of 2:1:1 (two parts of Ngasou, one part each of Dongae and Ngahei clay material) and pounded to make a powdery state by using the wooden mortar and pestle. The non-pounded, coarse granules are separated out using a bamboo sieve (ngeajande). Coarse granules that do not pass through the sieve is again pounded and shifted, and it may be repeated for two to three times. The finely powdered material is well kneaded by mixing little water till it becomes soft dough. It is again kneaded thoroughly. After that, well kneaded clay is ceded apart into many clay balls according to the size of the vessel to make. (Fig 8 and 9)

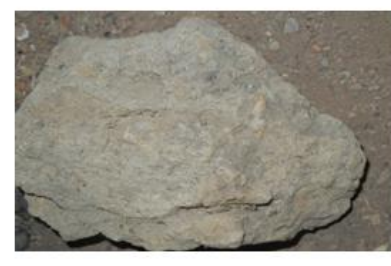

(a) Dry clay

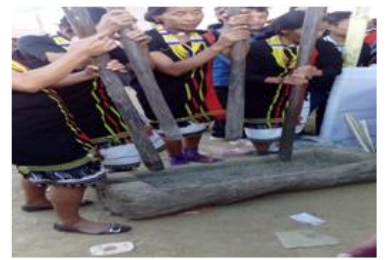

(d) Again pounding the course material

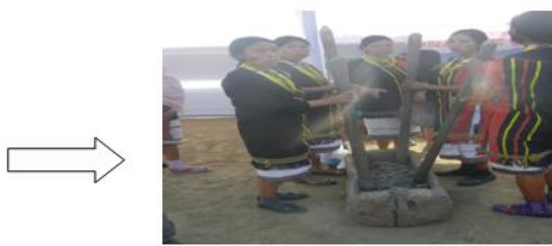

(b) Pounding of clay using Mortar and Pestle

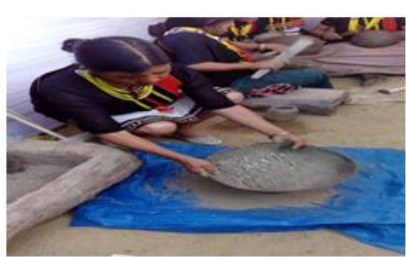

(c) Separating the course material through sieving

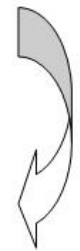

Fig 8:- Clay preparation in progress

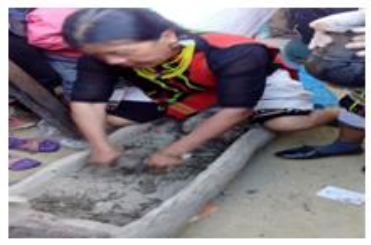

(a)Kneading Process

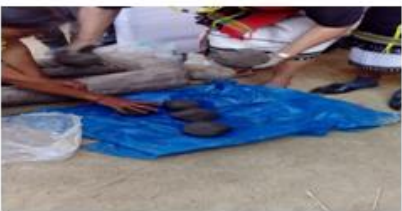

(d)Prepared soft dough
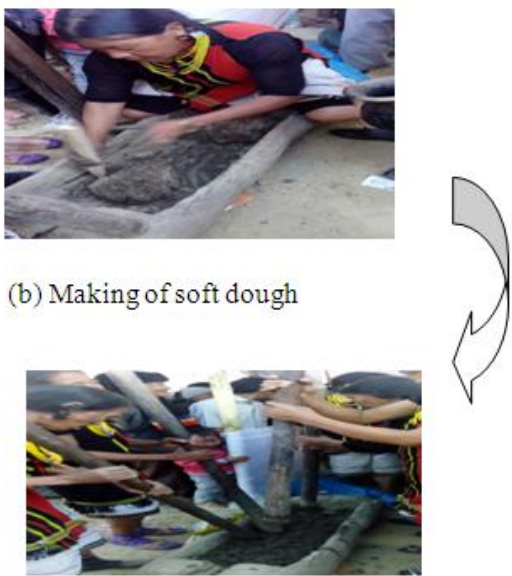
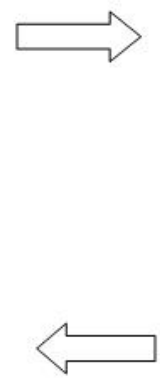

(b) Making of soft dough

(c) Pounding the mixed resources

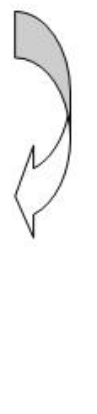

Fig 9: - Oinam Craftsperson at work

\subsection{Technique of production}

The Oinam craftsperson makes earthen vessels by their naked hands and it is an art of their hands. By sitting on a specially made wooden platform (pheng), potter kneads the clay thoroughly at the available space of the same platform where she sits. While doing so, a little water is sprinkled off and on over the platform and makes the clay balls flattened with her hands.

The very first stage of shaping an earthen vessel - the making or the 'preform' involves the potter's initial transformation of raw damp clay into a cylindrical shape. The flattened clay is wrapped around a cylindrical roller $(\mathrm{Vu})$ so as to get an elongated/cylindrical object with a desired length (Fig .10). After the wooden $\log$ is taken out slowly, a hollow and cylindrical shaped object of flattened clay is thus obtained. One 
hollow end is made closed with a flat piece of clay. This preform production is both 'transformative' (which makes a solid cylinder of clay having opens holes in both ends, without a base) as well as 'additive' (in which the potter gradually adds the total quantity of clay required). The suture between the joints is obliterated with fingers and also by using a tuta (protector). Body part of the vessel is prepared to gain its desired shape by the potter's hand grasping the cylindrical structure over the knees of the potters. During this process, the inner and outer surfaces are dampened by sprinkling a little water or saliva over it on and off. The neck and rim parts of the vessel are prepared by coiling method. Here, rolls of clay are spirally turned around to form the walls of the shoulder part till the desired height is achieved. Then, the wet beater (titu) is used. At the same time, the pot is rotated slowly by placing between the craftsperson's thighs so as to enable to mend eventually the outer surface of the vessel with the help of a water-soaked plain dabbler (titu) (Fig.11). Regularity of lip is adjusted by tapping with titu and with potter's fingers placing below by giving support, and then tapping with khouthing at the rim and shoulder parts. After this, the uneven surface of the rim is obliterated by shaving with the smoother (zha) and by rubbing with index finger. It is then sundried for three to four hours. After it becomes a little harder, beating the base of the pot starts. The base is enclosed by simply pushing and pinching. The excess part is taken off. Then the potter dilates the base portion by beating on the other surface with the beater (titu) while its force is counteracted from inner surface with an oval shaped stone (tuta) held by the other hand at the greatest diameter. After completion of the overall shaping, pots are decorated (in few cases), followed by shade drying for about a day(Fig 12). During this period light beating with the help of khouthing is done on the outer surface after every two to three hours' interval. After three or four days pots are ready for baking.

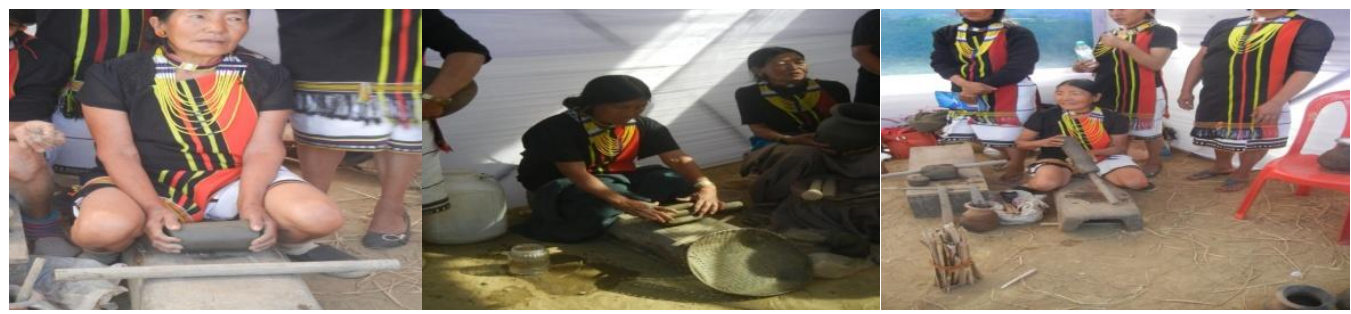

Fig 10:- Preform stage (transformation of raw damp clay into cylindrical shape)
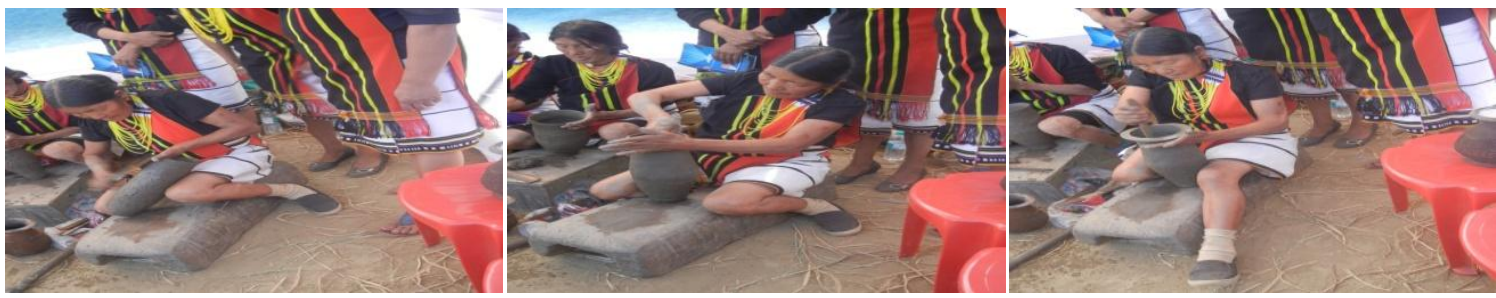

Fig 11: - Shaping with beater and giving final touch

\subsection{Decoration}

Decoration of earthen vessel is not done on all the pots they made. Some of the pots are left plain and it depends on the potters' choice as well as on the functional attributes assigned to the vessels they made. Decoration with cord marking is done by wrapping a piece of net made out of the cordage of bamboo splits, at around one end of the wooden paddle (khya, Fig. 7). The twilled cords are made with a specific bamboo species known as "Poh" (Bambusa Tulda) which are grown locally in the nearby forest. After the tender pieces of young bamboo culms are split, these are soaked in water for two to three days. These bamboo splits are later made into thin strands which are to be twisted together to make up yarn. Such cordage exhibits a character of twist direction creating a cordage with "S" direction of spinning motion of down and to the right. Two strands of cordage are then mesh together evenly and alternately to make a piece of net. (Fig.13a)

Another decorative pattern is the appliqué done at the neck and shoulder part of a globular jar.

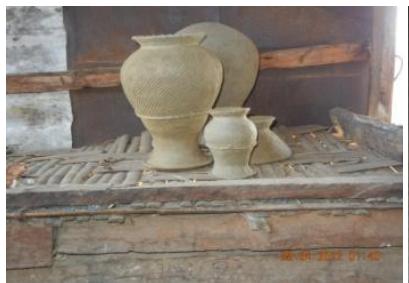

Fig 12:- Shade drying of pots

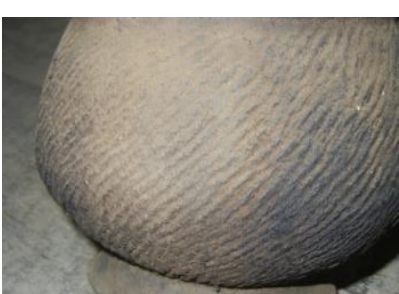

Fig 13a:- Design

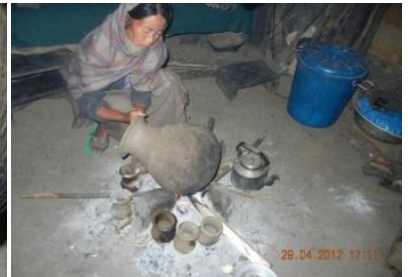

Fig 13b:-Warming of pots before firing 


\subsection{Firing}

Firing of green pots, being the last stage in the potmaking process is done at the open sites. The craftsperson strictly observed the social norm of sexual abstinence on the day before firing the pots. Male members also usually took part in such firing activities. Before proper firing, pots are to bake for a while to the heat of fire by placing them horizontally near it, as it controls the green pots from breakage or cracking while firing. Firing bed is made initially a layer of straws, upon which dry branches of mothing tree are placed. This is again covered with straws and twigs that look like a high heap of straw. After the straw and twigs are completely burnt, they checked whether the earthen pots are fully baked or not by inserting a long pole inside. When they are fully satisfied that the pots are well fired these are removed with great care with the help of a long wooden pole. (Fig.14)

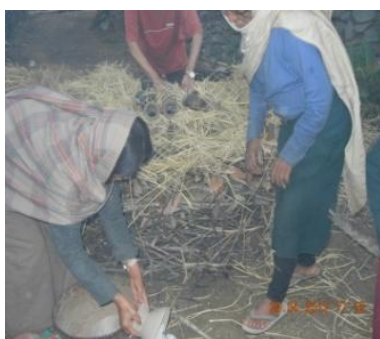

(a)Making bed for firing

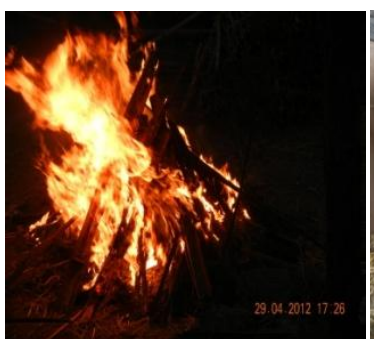

(b) firing

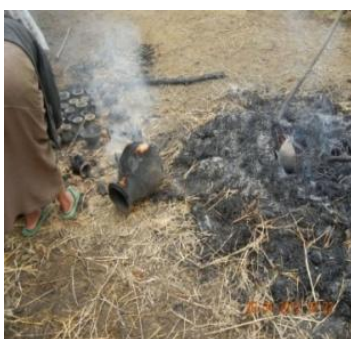

(c)

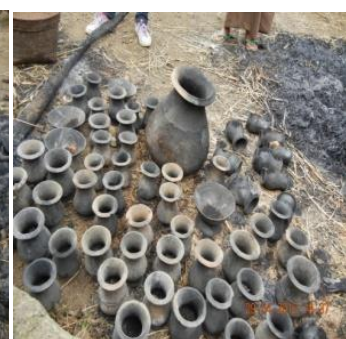

removing pot from fire

Fig 14: Firing the green earthen vessels

\subsection{Surface Treatment}

When the pots removed from the fireplace are still red hot, chaffs are thrown over them. It is believed that in doing so the hardness of the vessel accelerates. Again, the scraped bark of the paothing tree is rubbed against the outer wall of the pot after these are cooled down. At the final stage, the decoction of the bark of paothing tree, prepared well before, is poured inside the vessel and kept remain for about 10 days or so. And after that the pots are ready to use or to sell.

\section{Concluding Remark}

It is an agreed fact that ceramics indicate continuity or change in terms of the technological and decorative traditions ${ }^{[6][7][8]}$, and decorated pottery continues to be used in cross-dating and in testing of social relationships ${ }^{[9][10][11][12][13]}$. And, archaeologists also often turn to the study of ceramic technology as a cultural marker and used to distinguish between ethnic groups. Studying the contemporary ceramic production system has a number of archaeological significances - because of the reasons that potteries have their almost exasperating quantity as archaeological data ${ }^{[14]}[15]$; and they have potentials as vehicles for interpreting past production technology and organization ${ }^{[16][17][18]}$. However, attributes of ceramics are often highly stylistic, carrying meanings which complicate social boundaries. Of rising significances, the present discourse is on ceramic production technology and specific attributes of decoration among a Naga population in Manipur.

The occurrence of such decorative patterns on some earthen vessels of Oinam Poumai handmade pottery have archaeological significances in terms of this possible temporal continuity as a basic ceramic ethnographic character since early times till present. The female potters being traditional producers operate the craft on a seasonal part-time basis forming the vessels by molding and the paddle-and-anvil techniques. Handmodeling, being the most basic and oldest method of manipulating clay is skillfully used by the potters to produce functionally varied earthen pots. They decorate vessels with a combination of appliqué and cordmarking. Thus, among the population under study, cord-marking is a relatively popular method of ceramic decoration And this is done after obtaining the desired shape by beating with a plain beater (khya) which leaves impressions on the outer surface of the pottery. In fact, this method of decoration requires a potter to impress twisted cordage into the wet clay of a freshly made vessel, leaving a negative impression of the cordage as decoration on the ceramic. This cordage exhibits an attribute referred to as final twist direction, referring to the direction the fibers were spun in the creation of the cordage.

In fact, the temporal extension of cord-marked pottery in Southeast Asian dates back to later Hoabinhian period of Early Holocene times. The distribution and archaeological significance of such decoration is well known since it occurs as a dominant ceramic ware in association with chipped and ground stone tools including shouldered celts over a wide range in the East Asia and Southeast Asia ${ }^{[19][20][21]}$. It is asserted that a determinative role in the emergence of pottery is played by East Asia where the antiquity of pottery dates back to ca. 20,000 cal BP in otherwise Late Paleolithic contexts during the Last Glacial Maximum in South China some ten millennia before the time when sedentary, Early Neolithic villages first appear in China ${ }^{[22][23]}$. Of the three prehistoric technological and economic developments in South East Asia, Solheim II ${ }^{[24]}$ was of the 
opinion that the manufacture of cord-marked pottery as well as the domestication of one plant or animal is the diagnostic of the late Hoabinhian with its existence in Mainland Southeast Asia between 15,000 and 10,000 B.P. And also, 'the manufacture of cord-marked pottery could have been invented in one of the subcultures of the Hoabinhian technocomplex, or it could have been borrowed from another, as yet unknown culture' (P. 151).

The present finding also has ethnoarchaeological significances in postulating not the probable prehistoric technology of ceramic production but also decoration pattern more particularly the cord-impression. Another important feature of Poumai ceramic technology is its initial stage of molding where flattened clay is wrapped around a cylindrical roller (vu) to get an elongated/cylindrical shaped object with a desired length. From these very cylindrical shaped stuff earthen vessels of desired shape and form is to create. One of the fascinating analogies of such features, that is, clay cylinders is with those found in an excavated prehistoric mound at Khok Phanom Di Site in Central Thailand dated between 2000 and 1500 B.C ${ }^{[25]}$. The site is a mortuary mound where females were buried with specialist potting equipment ${ }^{[26]}$ and other significant finds include clay net sinkers, bone points and awls, stone adzes, hoes, shell knives, shell beads and bangles, potters' anvils and burnishing stones, clay cylinders, and extraordinary pottery and potsherds, etc. This prehistoric example of clay cylinders from prehistoric Thailand entails the very antiquity of molding technology in ceramic production technology, which is still in vogue among the Poumai potters in Manipur. And this also has referred to an analogy found with those found from archaeological contexts in Manipur ${ }^{[27]}$.

Cord-marked pottery also seems to be ubiquitous in North East India. Being a probable extension of Eastern and South Eastern Asian Hoabinhian and Neolithic element, such decorated potsherds are found from different excavated sites such as, Daojali Hading ${ }^{[28]}$ and Sarutaru ${ }^{[29]}$ in Assam; some sites in Garo Hills ${ }^{[30][31]}$; Parsi-Parlo in Arunachal Pradesh ${ }^{[32]}$; Napachik and Phunan sites in Manipur ${ }^{[33]}$; Pynthorlangtein ${ }^{[34]}$ and Khasi and Jaintia hills in Meghalaya ${ }^{[35]}$; some sites from Nagaland ${ }^{[36]}$, etc also belongs to this East Asian Neolithic tradition. On the other hand, this character may also be taken as an important component of Northeast Indian Neolithic pottery ${ }^{[35]}$.

On the basis of the manufacturing technique and decorative pattern, it may not be a farfetched assumption that the potmaking tradition of the Poumai tribe of the village is a continuing technology since the early days as did by their prehistoric predecessors. And obviously this may give us hopeful insights of the past ceramic tradition, such as the identity of artisans, social boundaries and craft monopoly by sex, and spatial dimension in pot making, etc - which can go with the theoretical paradigm of ceramic ethnoarchaeology.

\section{References}

[1] Van Den Bel., Martijn. . The Palikur Potters: an ethnoarchaeological case study on the Palikur pottery tradition in French-Guiana and Amapá, Brazil. Bol. Mus. Para. Emílio Goeldi. Ciências Humanas, Belém, 4 (1): 39-56.2009

[2] Gould, R.A.. The Anthropology of Human Residues. American Anthropologist, 80 (4): 815- 835.1978

[3] Skibo, J. M; M. B.Schiffer; and N. Kowalski. Ceramic style analysis in Archaeology and Ethnoarchaeology: Bridging the analytical gap. Journal of Anthropological Archaeology, 8:388-409.1989

[4] Longacre, W. A. 'Ceramic ethnoarchaeology: An introduction'. In, Longacre, W. A. (ed.) Ceramic Ethnoarchaeology Pp.1-10. Tucson: University of Arizona Press.1991

[5] Hamilakis, Y. Archaeological Ethnography: A Multitemporal Meeting Ground for Archaeology and Anthropology. Annual Review of Anthropology, 40: 399-414.2011

[6] Carlson, R.L.,. White Mountain Redware: A Pottery Tradition of East-Central Arizona and Western New Mexico. Anthropological Papers of the University of Arizona 19. Tucson. 1970

[7] Crown, P.L., and W.H. Wills, The Origins of Southwestern Ceramic Containers: Women's Time Allocation and Economic Intensification. Pp. 173-86 in The Archaeology of Gender in the American Southwest (ed. by K.A. Spielmann). Journal of Anthropological Research 51(2). 1995

[8] Bishop, R.L., and F.W. Lange,. The Ceramic Legacy of Anna 0. Shepard. Niwot, Colo.: University Press of Colorado. 1991

[9] Bunzel, R.L.,. The Pueblo Potter: A Study of Creative Imagination in Primitive Art. New York: Columbia University Press.1929

[10] Duff, A.I. An Exploration of Post-Chacoan Community Organization through Ceramic Sourcing. M.A. thesis, Arizona State University, Tempe, 1993

[11] Shepard, A.O., The Technology of Pecos Pottery. Pp. 389-587 in The Pottery of Pecos, vol. 2 (by A.V. Kidder and A.O. Shepard). Papers of the Phillips Academy Southwestern Expedition 7. New Haven, Conn: Published for Phillips Academy by Yale University Press. 1936

[12] Rice, P.M., Recent Ceramic Analysis, pt. 1: Function, Style, and Origins. Journal of Archaeological Research 4(2):133-63. 1996a

[13] Rice, P.M., Recent Ceramic Analysis, pt. 2: Composition, Production, and Theory. Journal of Archaeological Research 4(3):165$2031996 b$

[14] Willey, G. R. Volume in Pottery and the Selection of Samples. American Antiquity 27:230-231.1961

[15] Sullivan, A. P. Prehistoric Southwestern Ceramic Manufacture: The limitations of the current evidence. American Antiquity 53:2335.1988

[16] Arnold, D.ECeramic Theory and Cultural Process. Cambridge:. Cambridge University Press 1985

[17] Kramer, C. . Ceramic ethnoarchaeology. Annual Review of Anthropology 14:77-102.1985

[18] Rice, P. M. Pottery Analysis: A Sourcebook. Chicago: University of Chicago Press.1987

[19] Cheng Te-K’Un. Archaeology in China, I: Prehistoric China. Cambridge.1959

[20] Chang, K.C. Archaeology of Ancient China. New Haven.1963b

[21] Gormon, C. In worlds archaeology 2 Pp. 300-320.1971

[22] Cohen, D. J. The Beginnings of Agriculture in China: A Multi-Regional View. Current Anthropology, 52(S4): S273-S293.2011

[23] Wu, X.; C.Zhang; P.Goldberg; D.Cohen; Y.Pan; T.Arpin; and Bar-Yosef, O. 2012. Early Pottery at 20,000 Years Ago in Xianrendong Cave, China. Science 336(6089):1696 -1700 
[24] Solheim II, W.G. Northern Thailand, Southeast Asia, and World Prehistory. Asian Perspectives. XIII: 145-162.1970

[25] Higham, C.F.W. and R. Thosarat. 2004. The Excavation of Khok Phanom Di: A Prehistoric Site in Central Thailand. Volume VII: Summary and Conclusions. London: Society of Antiquaries

[26] Bentley, R. A.; N. Tayles; C. Higham; C. Macpherson and T. C. Atkinson. Shifting Gender Relations at Khok Phanom Di, Thailand Isotopic Evidence from the Skeletons. Current Anthropology, 48 (2): 301-314. . 2007

[27] Singh, O.K... Cord-marked Pottery Making Tradition in Manipur. Puratattva 29: 60-61. 1998-99

[28] Sharma, T.C. Prehistoric Archaeology of Assam - A Study of the Neolithic Culture, Unpublished Ph.D. Thesis, University of London. London.1966

[29] Rao, S.N. Excavation at Sarutaru: A Neolithic Site in Assam. Man and Environment 1: 39-42.1977

[30] IAR: Indian Archaeology: A Review . Annual Bulletin of Archaeological Survey of India, New Delhi.1966-67

[31] IAR: Indian Archaeology: A Review . Annual Bulletin of Archaeological Survey of India, New Delhi.1967-68

[32] Ashraf, A. A. Prehistoric Arunachal: A study on Prehistory and Ethnoarchaeology of Kamla Valley. Itanagar: Directorate of Research, Arunachal Pradesh. 1990.

[33] Singh, O.K. Stone Age Culture of Manipur. Unpublished Ph. D Thesis, Manipur University, Imphal.1993

[34] Taher, N. and L.S. Rao. A Neolithic Factory site at Pynthorlangtein. In, Jarrige, C. and V. Lefevre (eds.) Proceedings of the Sixteenth International Conferences of the European Association of South Asian Archaeologists, Paris, Vol. I: Prehistory, Pp. $02-06$ July 2001. Paris: Editions Recherche sur les Civilisations.2005

[35] Mitri, M. An Outline of the Neolithic Culture of the Khasi-Jaintia Hills of Meghalaya, India: An Archaeological Investigation. Oxford: British Archaeological Report Series 2013. 2009

[36] Nienu, V. Recent Prehistoric Discoveries in Nagaland - A Survey. Highlander, Research Bulletin, Dept. of Art and culture, Govt. of Nagaland. Vol. II, No. 1.1974 